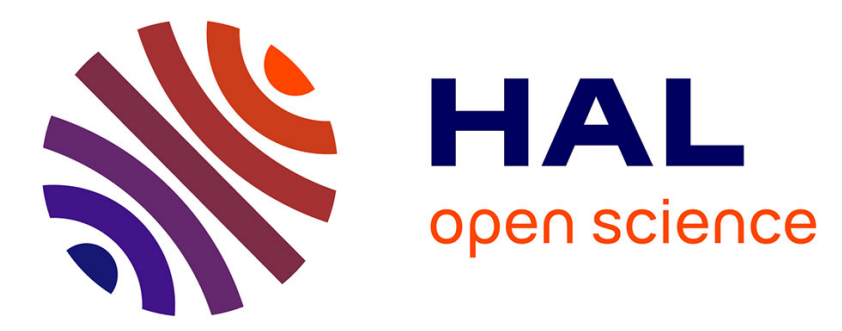

\title{
Scripting argumentative knowledge construction in computer-supported learning environments
}

\author{
Armin Weinberger, Karsten Stegmann, Frank Fischer, Heinz Mandl
}

\section{To cite this version:}

Armin Weinberger, Karsten Stegmann, Frank Fischer, Heinz Mandl. Scripting argumentative knowledge construction in computer-supported learning environments. F. Fischer, I. Kollar, H. Mandl, J.M. Haake. Scripting Computer-Supported Collaborative Learning Cognitive, Computational and Educational Perspectives, Springer, pp.191-209, 2006. hal-00190423

\section{HAL Id: hal-00190423 \\ https://telearn.archives-ouvertes.fr/hal-00190423}

Submitted on 23 Nov 2007

HAL is a multi-disciplinary open access archive for the deposit and dissemination of scientific research documents, whether they are published or not. The documents may come from teaching and research institutions in France or abroad, or from public or private research centers.
L'archive ouverte pluridisciplinaire HAL, est destinée au dépôt et à la diffusion de documents scientifiques de niveau recherche, publiés ou non, émanant des établissements d'enseignement et de recherche français ou étrangers, des laboratoires publics ou privés. 


\title{
Chapter 12
}

\section{SCRIPTING ARGUMENTATIVE KNOWLEDGE CONSTRUCTION IN COMPUTER-SUPPORTED LEARNING ENVIRONMENTS}

\author{
Armin Weinberger ${ }^{1}$, Karsten Stegmann ${ }^{2}$, Frank Fischer ${ }^{1}$, and Heinz Mandl ${ }^{3}$ \\ ${ }^{1}$ Knowledge Media Research Center, Tübingen; ${ }^{2}$ Eberhard-Karls-Universität, Tübingen; \\ ${ }^{3}$ Ludwig-Maximilians-Universität, Munich
}

\begin{abstract}
Computer-supported collaborative learning (CSCL) environments may encourage learners to engage in argumentative knowledge construction. Argumentative knowledge construction means that learners work together to elaborate on concepts by constructing arguments and counterarguments. This is achieved through discourse with the goal of acquiring knowledge within a specific domain. However, learners may encounter problems relating to one of three dimensions of argumentative knowledge construction. First, learners seem to have difficulties in constructing arguments that contribute to solving the task. Second, learners' arguments may lack important components such as data and warrants. Third, learners rarely build upon the arguments of their learning partners. Structuring argumentative knowledge construction with collaboration scripts is a promising instructional approach for facilitating specific process dimensions of argumentative knowledge construction. Little is known, however, about how to most effectively facilitate the acquisition of knowledge by directing collaboration scripts at specific dimensions of argumentative knowledge construction. This chapter will outline the theoretical background of argumentative knowledge construction and will then describe script components that target different dimensions of argumentative knowledge construction. The chapter will then discuss the empirical findings of two studies regarding the effects of these script components.
\end{abstract}

Collaborative learners are sometimes meant to construct and exchange arguments by collecting and balancing evidence and counterevidence through discourse with the goal of acquiring individual knowledge within a domain. Typically, however, learners do not work well on collaborative learning tasks in terms of constructing adequate arguments and interacting productively (Kuhn, Shaw, \& Felton, 1997; Mandl, Gruber, \& Renkl, 1996). Kuhn's work points out that even adult discussants rarely warrant or qualify 
their claims and thus rarely construct complete arguments. Furthermore, discussants are often unable to balance and integrate arguments and counterarguments critically. It has become clear that simply asking learners to collaborate is not sufficient for fostering argumentative knowledge construction (Mandl et al., 1996).

Asynchronous computer-supported collaborative learning has been regarded as a suitable context for facilitating argumentative knowledge construction (Andriessen, Baker, \& Suthers, 2003; Marttunen \& Laurinen, 2001). Learners communicate simultaneously or in an unspecified sequence via text-based interfaces and are thus able to type and read messages at their own individual pace. In this way, learners have more time than face-to-face learners to both compose their own messages and understand the messages of their learning partners. This time advantage may encourage learners with heterogeneous argumentation skills to take part in an argumentative debate. Besides the time advantage, learners who communicate asynchronously via computer can repeatedly access the arguments that have been already contributed and can easily revise the wording of their own arguments (see Pea, 1994). In text-based asynchronous communication, learners may compensate for individual deficits in learning prerequisites by investing more time in the reception and production of individual contributions. Learners may also take advantage of individual adaptive instructional support that is provided as part of the communication interface, such as computer-supported scripts. The question is, to what extent single script components could be directed at specific process dimensions of argumentative knowledge construction to improve individual knowledge acquisition. These could potentially be used to varying degrees, depending on how well the script components are able to compensate for the deficits of the student learning groups.

In this chapter, we first describe our approach to argumentative knowledge construction according to three process dimensions and their conceptual relationship to individual knowledge acquisition. Furthermore, we analyze how computer-supported script components may facilitate argumentative knowledge construction within these process dimensions. Finally, we summarize and discuss the results of two empirical studies that investigate the effects of computer-supported script components (with specific goal dimensions) on the processes and outcomes of argumentative knowledge construction. These studies have also been published in greater detail (see Weinberger, Ertl, Fischer, \& Mandl, 2005 and Weinberger, Stegmann, \& Fischer, 2005). 


\section{ARGUMENTATIVE KNOWLEDGE CONSTRUC- TION}

In argumentative knowledge construction, learners acquire knowledge through the elaboration of learning material by constructing arguments. Typically, argumentative knowledge construction scenarios are based on collaborative learning tasks (Leitão, 2000). For instance, learners may be provided with contrasting hypotheses about a problem and then argumentatively discuss, which hypothesis applies (Kollar, Fischer, \& Slotta, 2005). Learners also engage in argumentative knowledge construction when working on open-ended and complex problem cases for which they have to create and balance multiple hypotheses (Means \& Voss, 1996). Our approach to argumentative knowledge construction in collaborative, problem-based scenarios differentiates between three process dimensions, namely an epistemic dimension that describes arguments as steps towards solving the learning task, an argument dimension in which formal criteria for the composition of arguments are represented, and a dimension of social modes of co-construction that represents how learners interact with one another. This interaction is described in terms of how the learners relate their own arguments to the arguments of their learning partners (see Weinberger \& Fischer, 2006).

1) The epistemic dimension refers to the question of how learners work on the tasks they are confronted with, for example, by constructing relationships between the conceptual space and the problem space (Fischer, Bruhn, Gräsel, \& Mandl, 2002). Arguments may provide hypotheses on how to solve complex tasks. Learners relate the theoretical concepts of a given theory to the information in a problem. The epistemic dimension of arguments can indicate which concepts learners refer to and how learners connect concepts to solve a problem. This dimension can also show the extent to which learners are able to adequately apply knowledge. Collaborative learners do not always apply knowledge appropriately. When learners verbalize inappropriate applications of knowledge, there is a chance that their learning partners may adopt these misconceptions (e.g., Jeong \& Chi, 1999). In this respect, the epistemic dimension of arguments is an important component of argumentative knowledge construction. Depending on how well learners are able to construct arguments relating to the epistemic dimension, they may acquire adequate knowledge or misconceptions (Weinberger, 2003).

2) The argument dimension comprises how learners construct arguments with regard to defining formal relationships between specific components of arguments, such as claims, data, and warrants. Toulmin (1958) has put forward a structural model of single arguments that is made up of several components. In this model, a single argument consists of a claim, which is a conclusion that is being presented and justified in the argument. The claim is 
based on a datum, which is a fact that is supposed to support the claim. A warrant specifies the principle of how the datum supports the claim. Sometimes a warrant itself needs support, which is called backing. Thus, the backing indicates the principle upon which the warrant is based. Arguments may optionally also provide components that limit the validity of the claim and anticipate counterarguments. The qualifier indicates the extent to which the datum warrants the claim or may limit the validity of a claim. A rebuttal serves to anticipate parts of a counterargument that attack the data, the warrant, or the backing.

Toulmin's model poses an alternative to formal logic, which is closer to everyday reasoning in uncertain situations based on probabilities. However, Toulmin's model has been criticized for difficulties in distinguishing between the single components of the model in everyday argumentation, for example, distinguishing backing from data or differentiating between a qualifier and a rebuttal (Voss \& van Dyke, 2001). We will therefore apply a condensed argument model using the components of claim, datum with warrant and qualifier.

How is formal argumentation structure related to individual knowledge construction? When learners construct arguments they elaborate and selfexplain the learning material (Baker, 2003). These self-explanations help learners integrate new information into existing cognitive structures (Chi, Bassok, Lewis, Reimann, \& Glaser, 1989). In terms of Toulmin's model (1958), self-explanation could be described as a process of composing an argument from several components. From this perspective, learners are supposed to seek data that supports or opposes a claim, make an inference through a warrant that indicates how the data supports a claim, and limit the validity of a claim by constructing qualifiers.

3) The dimension of social modes of co-construction indicates how learners interact with one another. In this dimension, a number of social modes of co-construction and their relationship to individual knowledge construction have been identified. These indicate the different degrees to which learners operate using the reasoning of their peers (Fischer et al., 2002; Teasley, 1997). For instance, when building consensus in a conflict-oriented manner, learners need to pinpoint specific aspects of their peers' contributions and either modify them or present alternatives. In these terms, learners need to build their reasoning more closely upon the reasoning of their peers when working to build consensus in a conflict-oriented manner. This is in contrast to quick consensus building, that is, when learners only appear to accept the contributions of their learning partners in order to continue with discourse (Weinberger, 2003). The extent to which learners operate on the reasoning of what has been said before in discourse has been termed transactivity of dis- 
course, which is known to be positively related to individual knowledge acquisition (Teasley, 1997).

Table 12-1. Process dimensions of argumentative knowledge construction (see Weinberger \& Fischer, in press)

\begin{tabular}{ll}
\hline Process dimension & answers the question \\
\hline Epistemic dimension & $\begin{array}{l}\text { How do learners' arguments contribute to } \\
\text { solving the task? }\end{array}$ \\
Argument dimension & $\begin{array}{l}\text { How do learners construct arguments for- } \\
\text { mally? }\end{array}$ \\
Dimension of social modes of co-construction & $\begin{array}{l}\text { To what extent do learners operate on the } \\
\text { reasoning of their learning partners? }\end{array}$ \\
\hline
\end{tabular}

In summary, we propose to include three process dimensions for the analysis and facilitation of argumentative knowledge construction based on problem-oriented learning tasks (see Table 12-1). The processes of argumentative knowledge construction can be analyzed on a) an epistemic dimension (constructing arguments that contribute to solving a task), b) an argument dimension (building formally complete arguments), and c), a dimension of social modes of co-construction (operating on the reasoning of learning partners).

\section{SCRIPT COMPONENTS FOR ARGUMENTATIVE KNOWLEDGE CONSTRUCTION}

Argumentative knowledge construction is based on the assumption that learners need to construct arguments appropriately in order to benefit from collaborative learning environments. One approach for facilitating the outcomes of argumentative knowledge construction is to support learners in constructing arguments appropriately. Collaboration scripts provide an instructional approach that aims to facilitate the processes of argumentative knowledge construction.

Collaboration scripts were initially developed to encourage college students working in dyads to acquire knowledge from texts on the natural sciences (O’Donnell \& Dansereau, 1992). Collaboration scripts provide more or less explicit and detailed instructions for small groups of learners on what activities need to be executed, when they need to be executed, and by whom they need to be executed in order to foster individual knowledge acquisition.

Prototypical scripts are instructed prior to collaborative learning. Participants are trained to engage in the scripted collaborative activities, which are in turn supposed to facilitate the individual acquisition of knowledge. In computer-supported collaborative learning, there is typically no opportunity for antecedent collaboration training. Thus, computer-supported collabora- 
tive learning (CSCL) is often facilitated by the design of the interface (Baker \& Lund, 1997; Scardamalia \& Bereiter, 1996). Learners communicating via these interfaces are, to varying degrees, implicitly guided to engage in activities, as the interface suggests or limits specific discourse activities (Runde, Jucks, \& Bromme, this volume). Computer-supported scripts similarly aim to directly influence the interaction patterns of collaborative learners rather than train learners prior to actual collaboration.

When analyzing collaboration scripts in the context of argumentative knowledge construction, it can be noted that scripts typically aim to facilitate different process dimensions simultaneously. For instance, prototypical scripts may support epistemic activities, for example, summarizing a paragraph, as well as specific social modes, for example, criticizing the contributions of the learning partner (O'Donnell \& Dansereau, 1992). Little is known about the effects of single script components that target specific process dimensions on knowledge construction. In research on collaboration scripts, Larson and colleagues (1985) compared the effects of script components with different, specific goal dimensions, namely an elaborative and a metacognitive script component. The elaborative script component supported elaborative activities by modeling the role of a recaller, who was given the task of personalizing information or of using imagery to help remember the learning material. The metacognitive script component modeled the role of a listener who was given metacognitive tasks, such as error detection. The metacognitive script component impeded individual knowledge construction, whereas the elaborative script component facilitated individual knowledge construction. This study thus indicates that differentiated effects can be expected from script components with specific goal dimensions. Larson and colleagues (1985) argued, for instance, that some script components may also distract learners from learning goals. It is important to expand research on script components with single goal dimensions in order to better understand why and what kind of script components facilitate argumentative knowledge construction. The research should also analyze possible side effects that single script components may have on the processes and outcomes of argumentative knowledge construction. We may thus accumulate knowledge on how multiple processes of argumentative knowledge construction interact and affect individual knowledge acquisition.

With reference to the framework of argumentative knowledge construction, we differentiate between epistemic script components, argumentative script components, and social script components (Weinberger \& Fischer, 2006).

Epistemic script components aim to structure the discourse activities of collaborative learners with respect to the content of the discussion and with regard to the steps towards solving the task. Epistemic script components 
may support learners in finding adequate task strategies and may ask learners to elaborate on aspects of the task they would not normally consider (cf. Reiser, 2002). Approaches that we classify as epistemic script components may thus map expert-like strategies onto the interaction of learners (Dufresne, Gerace, Thibodeau Hardiman, \& Mestre, 1992; Herrenkohl and Guerra, 1998). For instance, these components provided collaborative learners with task strategies such as predicting and theorizing, summarizing results, and relating predictions and theories to results. As these qualitative studies indicate, epistemic script components may need to be reinforced by social script components.

Argumentative script components aim to support the construction of arguments in terms of warranting and qualifying claims based on argument models such as Toulmin's (1958). Argumentative script components aim to help learners construct formally adequate arguments and thus better elaborate the learning material (Andriessen et al., 2003). As learners supplied with argumentative script components are supposed to formulate better arguments in discourse, learners may also acquire knowledge on how to argue within a scientific domain.

Social script components specify and sequence the interaction of learners in order to promote knowledge construction (King, 1999). Social script components may thus support learners to engage in adequate interaction strategies that they would not apply spontaneously. For instance, social script components may facilitate transactivity by asking learners to respond critically to the contributions of their learning partners. Social script components typically also have learners rotate to work on different activities (e.g., Herrenkohl \& Guerra, 1998). The reciprocal teaching approach (Brown \& Palincsar, 1989), for instance, assigns the roles of a teacher and a learner for various text comprehension tasks.

In summary, prior research on different script components found that not all components are equally effective for promoting knowledge construction. Some script components appear to distract learners from the actual task or replace central learning activities rather than support learners in engaging in the activities themselves. To date, there has been little systematic research on the effects that various script components have on argumentative knowledge construction. Furthermore, most research on scripts deals with trained faceto-face learning environments rather than computer-supported scripts. Therefore, there is little knowledge about how specific computer-supported script components with different goal dimensions can facilitate the processes and outcomes of argumentative knowledge construction. 


\section{GOALS OF THE EMPIRICAL STUDIES}

The goal of the empirical studies is to investigate the effects of computersupported epistemic, argumentative and social script components on argumentative knowledge construction. These single script components focus on different process dimensions of argumentative knowledge construction and may have differentiated effects on its outcomes. We conducted two studies in order to investigate how individual computer-supported script components can facilitate argumentative knowledge construction (for further details see Weinberger, Ertl, et al., 2005; Weinberger, Stegmann, et al., 2005).

\section{METHOD}

The results are based on a one factorial analysis and single group comparisons of the experimental groups with epistemic, social, and argumentative script components with the control group. Each experimental group in the two studies consisted of 24 students. Thus, 96 participants in 32 groups of three entered the statistical analyses. The methods that were used in each of the studies were identical.

\subsubsection{Sample and setting}

First-semester educational science students from the University of $\mathrm{Mu}-$ nich participated in the studies. The students took an obligatory introduction course to educational science. One of the regular face-to-face sessions of the course was transformed into an online learning session. Participation in this session was required in order to receive a course credit at the end of the semester. The learning outcomes of the experimental session, however, did not count towards the students' overall performance. The introduction course sessions normally consist of a one hour lecture and a successive two hour seminar. Similarly, the collaborative online learning session took three hours. The students were randomly assigned to the experimental conditions in groups of three. Participants in each group of three were separated from each other in different laboratory rooms and communicated asynchronously with the help of web-based discussion boards in a computer-supported learning environment. 


\subsubsection{Learning task}

The task of the participants was to apply the attribution theory of Weiner (1985) to three problem cases (see Table 12-2 for an example of a problem case) and reach agreement on a final analysis for each case.

Table 12-2. One of the three problem cases, namely the "math case", learners needed to analyze and discuss

As a student teacher in a high school, you participate in a school counseling session with Michael Peters, a pupil in the $10^{\text {th }}$ grade.

"Recently I've started to realize that math is just not my thing. Last year I almost failed math. Ms. Weber, my math teacher, told me that I would really have to make an effort if I wanted to pass $10^{\text {th }}$ grade. Actually, my parents stayed pretty calm when I told them this. First mom said that nobody in our family is a math whiz. My father just kept smiling and told the story about how he cheated on his final math exams by copying from other students and using cheat sheets. 'The Peters family,' he said, 'has always been a math teacher's nightmare'. Once when I was slightly tipsy at a school party, I told this story to Ms. Weber. She said that it was not a bad excuse, but not a good one either. She said it was just one of a number of excuses you could come up with to justify being lazy. Last year I barely made it through mathematics, so I am really nervous about the upcoming school year!"

The descriptions of the problem cases were embedded into the web-based learning environment, so that the participants could study the problem case while composing new messages on the web-based discussion boards.

\subsubsection{Computer-supported learning environment}

All groups collaborated in three web-based discussion boards - one for each case. The web-based discussion boards provided a main page with an overview of all message headers. In this overview, answers to original messages appeared in outline form. The learners could read the full text of all messages, reply to the messages, or compose and post new messages. In the replies, the original messages were quoted out with $>$ as in standard newsreaders and e-mail programs.

\subsubsection{Procedure}

Prior to collaboration, the randomization of participants was successfully controlled using individual questionnaires and tests, for example, on prior knowledge, ambiguity tolerance, and computer experience. Subsequently, learners were able to study a three page summary of the attribution theory for 15 minutes. Learners were allowed to make notes and keep the text and their notes during the collaborative phase. The collaboration time, in which 
learners communicated with each other via asynchronous, text- and webbased discussion boards, was 80 minutes in all experimental groups. All discourse activities were recorded within the web-based discussion boards to collect data on the dimensions of argumentative knowledge construction. The experimental conditions differed only with respect to the computer-supported script components that were implemented using the interface of the computer-supported environment. After collaboration, learners were tested for individual domain-specific knowledge using individual post-tests similar to the pre-tests on prior knowledge.

\subsubsection{Instruments}

In order to analyze the extent to which the script components influenced the processes of argumentative knowledge construction, we segmented and analyzed each of the single arguments the learners put forward in the written discourse on the epistemic dimension, the argument dimension, and the dimension of social modes of co-construction. On the epistemic dimension we differentiated, for instance, between adequate or inadequate arguments in terms of the relationships the learners constructed between concepts and case information. With respect to the argument dimension, we coded the completeness of arguments according to a model of arguments consisting of claim, datum with warrant, and qualifier. We also coded the arguments with regard to their social mode. The interrater reliability was sufficiently high (for a detailed description of the process analyses see Weinberger \& Fischer, 2006).

Pre- and post-tests consisted of problem cases comparable to the three cases learners were asked to analyze during the collaborative phase. The case analyses the learners needed to produce in the pre- and post-tests were segmented into units consisting of a theoretical concept applied to problem case information. In a manner similar to the process analysis, these units were coded with respect to their adequacy in terms of the relationships learners constructed between theoretical concepts and case information to indicate domain-specific knowledge. The adequacy of the individual learner's case analyses in the pre- and post-test was determined by their fit to expert solutions of the problem cases. These expert solutions particularly stressed the application of multiple perspectives to the cases.

More detailed information on different aspects of the quantitative analyses of the individual empirical studies has been provided in various publications (e.g., Weinberger, 2003; Weinberger, Ertl, et al., 2005; Weinberger \& Fischer, 2006). 


\subsubsection{Treatments}

The following experimental groups were examined in Study 1:

The control groups accessed the three distinct web-based discussion boards of the CSCL environment to read or contribute messages. When composing a new message, learners were free to choose to start a new discussion thread or to reply and contribute to an existing discussion thread.

The epistemic script component group could access and contribute to the web-based discussion boards in a manner identical to the control group, but whenever a new discussion thread was started, the text window was structured with prompts of the epistemic script component. These prompts asked learners to separate relevant from irrelevant case information, structured how learners applied theoretical concepts to the problem cases, and asked learners to suggest future developments of the case and pedagogical interventions (see Figure 12-1).

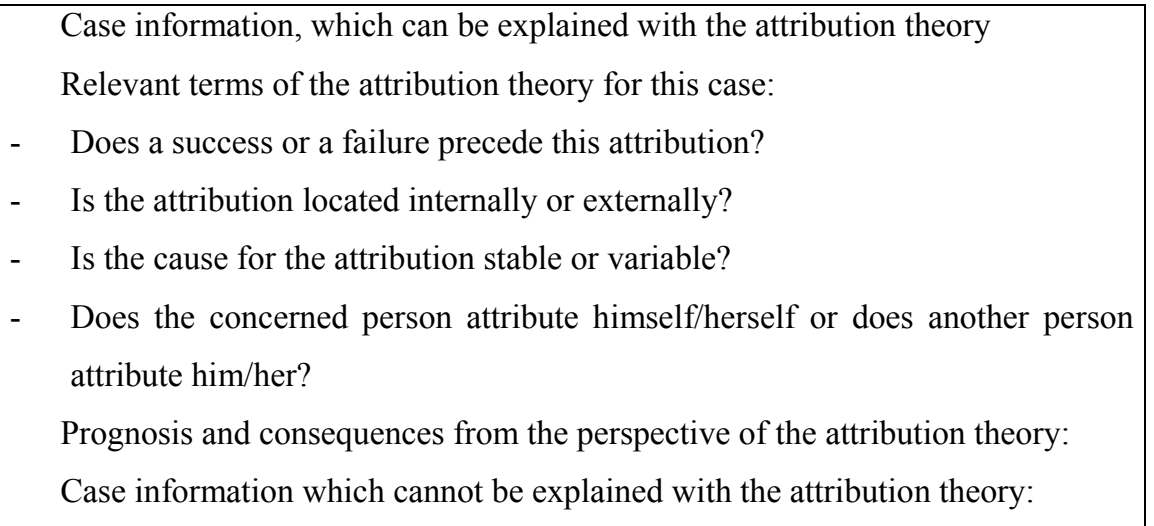

Figure 12-1. Prompts of the epistemic script component to apply the concepts of Weiner's (1985) attribution theory to problem cases.

The groups with the argumentative script component were provided with three text windows named claim, datum with warrant and qualifier. Learners were supposed to collect at least one datum for their claim, explicit the warrant for how the datum supports the claim, and provide a qualifier for their claim by filling out all three text windows (see Figure 12-2). Subsequently, learners could click an "Add"-Button which displayed the three argument components in the actual text window of the web-based discussion board. Learners could add any number of arguments in the main text window. 


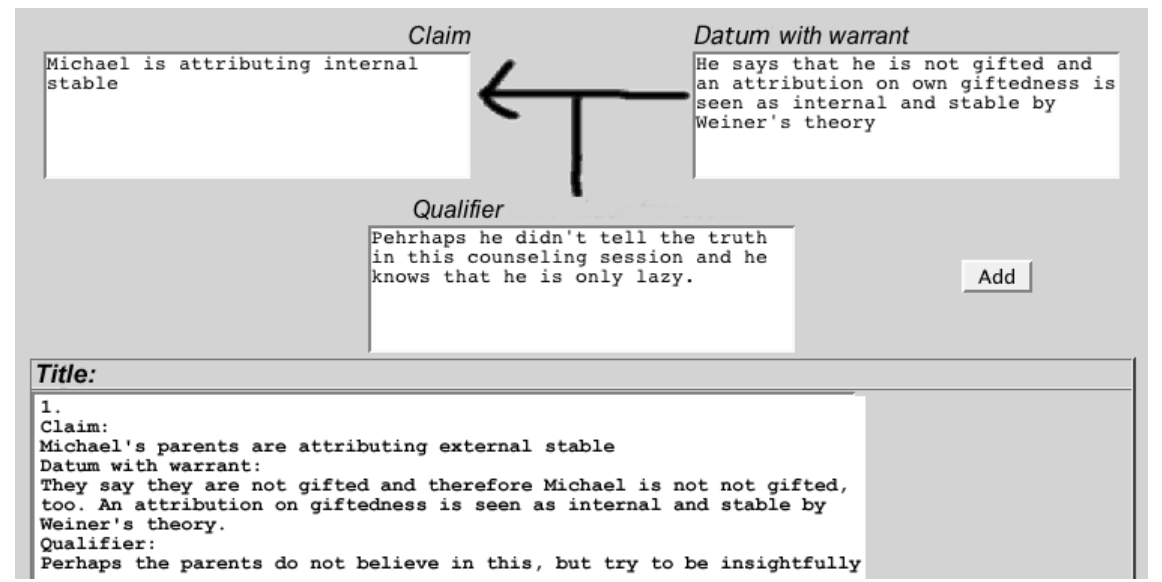

Figure 12-2. User interface realizing the argumentative script component with four text windows: claim, datum with warrant, qualifier, and message body.

The learners in the social script component groups were assigned two roles - a) analyst for one of the cases with the task of composing initial and concluding analyses of the case and responding to critiques, and b) constructive critic for the other two cases with the task of repeatedly criticizing the case analyses. The number of messages was determined by the social script component (one initial case analysis, two critiques, two replies to the critiques, two more critiques and one concluding analysis). These messages given by the social roles were automatically sequenced, that is, learners were led through each discussion board to submit eight messages in total (see Figure 12-3). Furthermore, the single messages were supported by prompts within the text windows such as "These aspects are not clear to me yet", "We have not reached consensus concerning these aspects" or "My proposal for an adjustment of the analysis is". 


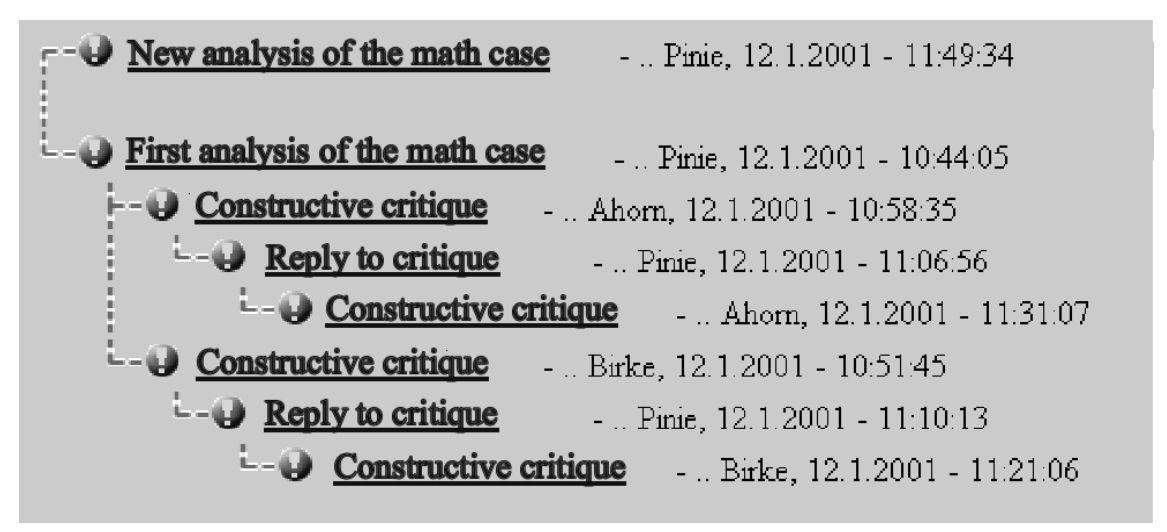

Figure 12-3. Structure of a discourse supported with the social script component with an initial analysis of the math case, two constructive critiques, two replies of the case analyst to the critiques, two more critiques and a new analysis of the case by the case analyst.

\section{RESULTS}

The epistemic script component reduced the amount of off-topic discourse and focused learners' discourse on just a few new and adequate knowledge concepts. The learners who were supported by the epistemic script component contributed more to solving the problem cases than learners without the script component (see Table 12-3; see also Mäkitalo, Weinberger, Häkkinen, Järvelä, \& Fischer, 2005; Weinberger, 2003; Weinberger, Ertl, et al., 2005).

Table 12-3. Example of a learner's message with a case analysis supported with the epistemic script component.

Does success or failure precede this attribution?

- failures

Is the attribution located internally or externally?

- internal

Is the cause for the attribution stable or variable?

- Michael and his parents: stable causes (talent)

- Teacher: variable causes (effort)

Who is attributing? Self or other?

- Michael

- His parents

- The teacher 
The epistemic script component, however, also affected the argument dimension and the dimension of social modes of co-construction. Learners with the epistemic script component constructed less formally complete and less transactive arguments than learners without the epistemic script component.

The argumentative script component reduced off-topic discourse and facilitated the formally adequate construction of single arguments. Learners with the argumentative script component warranted and qualified their claims substantially more frequently than learners without this script component (see Table 12-4).

Table 12-4. Example of a learner's message with a case analysis supported with the argumentative script component.

Claim:

in this case, it has to be an internal stable attribution

Datum with warrant:

parents say that 1.) the whole family was not "witty" in math and the father adds that he barely passed his math exam.

internal because talent is to be located within the person and stable because talent does not change.

Qualifier:

i can't think of any

However, this script component also impeded the content quality of the single arguments and reduced the adequate application of new knowledge concepts that were to be learned (see also Weinberger, Stegmann, et al., 2005).

The social script component reduced off-topic discourse and facilitated the dimension of social modes of co-construction of argumentative knowledge construction. The discourse of groups with the social script component was more critical and transactive than the discourse of groups of learners without social script component (see Table 12-5).

Learners supported with this script component operated more on the reasoning of their learning partners. Additionally, the social script component seemed to foster epistemic activities. Learners supported with this script component engaged more frequently in epistemic activities to solve the problem case than learners without this script component (see also Weinberger, 2003; Weinberger, Ertl, et al., 2005 for more detailed process analyses). 
Table 12-5. Example of a learner's critical reply supported by the social script component.

These aspects are not clear to me yet:

What attribution according to attribution theory can be applied? If mother is not

talented - so is the son?

We have not yet reached consensus concerning these aspects:

The teacher does mention that it is only his laziness; she doesn't explain it to

him, however.

My proposals for an adjustment of your analysis:

Proposal for a solution: Parents should attend a re-attribution training!

Regarding individual knowledge acquisition, large improvements were observed between pre- and post-test for learners in all experimental groups, including the control group. The results further support the notion that the acquisition of individual domain-specific knowledge can be influenced by specific script components implemented within CSCL environments. The epistemic script component impeded the individual acquisition of knowledge compared to the control group. The argumentative script component did not facilitate knowledge acquisition beyond the levels of the control group. The social script component, however, proved to support the individual acquisition of domain-specific knowledge. After the collaborative learning phase, learners provided with the social script component were better able to individually apply different concepts to problem cases than learners without the social script component (see Weinberger, Ertl, et al., 2005; Weinberger, Stegmann, et al., 2005).

\section{CONCLUSIONS}

The studies investigated the effects of different script components on argumentative knowledge construction in computer-supported learning environments. The learning environments investigated differed only with respect to the script components, namely (1) the epistemic script component, which structured how learners handled the task and which concepts they used, (2) the argumentative script component that asked learners to warrant and qualify their claims, and (3) the social script component that aimed to facilitate how learners interacted with each other. All computer-supported script components substantially reduced off-topic discourse and facilitated the specific processes of argumentative knowledge construction that they were focusing on. Based on these findings, all script components seem to have the general effect of focusing learners on the task. Script components guide and inform learners of what to do next to solve the task in one way or another. There- 
fore, learners seem to have less opportunity to engage in off-topic discourse. Apart from this general effect, script components can be very specific. Script components with single goal dimensions can be implemented deliberately into CSCL environments to address specific shortcomings in the interaction of groups of learners rather than providing a "one-script-fits-all" model.

The results indicate that epistemic script components help learners to construct arguments that contribute to solving problem cases, but that learners do not necessarily benefit from this support with regard to individual knowledge acquisition. One explanation for this could be that epistemic script components might not sufficiently support joint elaboration of the learning material, but rather function as checklists. Thus, epistemic script components may enable learners to solve the tasks with a limited elaboration of the learning material. In order to avoid this elaboration-reduction-effect, epistemic script components may need to be faded out. It may also be necessary in some cases to make collaborative learning tasks harder instead of simplifying the collaborative learning task in order to facilitate the active elaboration of the learning material (Palincsar \& Herrenkohl, 1999; Reiser, 2002). Furthermore, the degree to which epistemic script components demand the elaboration of learning material or "micromanage" the task may depend on the prior knowledge of the participants. It may prove unnecessary to provide epistemic script components to learners with above-average prior knowledge and skills. Advanced learners may already possess functional strategies for solving a task and additional epistemic scripting might simply distract learners from the actual task (see Larson et al., 1985). In order to avoid this over-scripting effect (Dillenbourg, 2002), epistemic script components may need to be carefully matched with the individual prior knowledge of the participants. Too much or too detailed epistemic scripting may impede the elaboration of the learning material and the interaction of learners; particularly when the script oversimplifies the task and divides it into subtasks that can be worked on by each learner individually (Cohen, 1994).

The argumentative script component, like the other script components, facilitated the process dimension that it targeted. This study showed that argumentative script components are able to support argumentative knowledge construction in both the formal argumentation process dimension during discourse and individual knowledge acquisition. Scripting the construction of arguments may support learners in elaborating the learning material. By constructing formally complete arguments with claim, datum, warrant, and qualifier, learners need to self-explain the learning material, which may facilitate the acquisition of knowledge (Baker, 2003). Learners supported with the argumentative script component may have elaborated the learning material better than learners without the script. Learners did not always use the appropriate concepts to solve the task, however, and may thus have elabo- 
rated prior knowledge using misconceptions rather than the knowledge that was to be learned. Argumentative script components in this way may function as a thinking tool to amplify elaboration, but fail to prompt learners to use the relevant knowledge concepts that are to be learned.

The results further indicate that social script components may facilitate social modes of co-construction, epistemic activities, and the individual acquisition of knowledge. Collaborative learners without support from a social script component often build a minimal consensus in order to hastily complete collaborative tasks or do not collaborate on the learning task at all. In contrast, social script components support learners in inquiring about the contributions of the learning partners more critically and thereby help them acquire more knowledge individually than learners without additional support in the dimension of social modes of co-construction (see King, 1999; Palincsar \& Herrenkohl, 1999). This critical approach to the contributions of the learning partners has also appeared to facilitate the elaboration of the learning material. One explanation could be that socially scripted learners engaged in more transactive discussions and appeared to benefit to a greater extent from the contributions of their learning partners (Teasley, 1997). Another explanation is that learners with the social script component elaborated the learning material to a greater extent, because they anticipated critique from their learning partners. This explanation is in line with studies that indicate that only the expectation of externalizing knowledge facilitates learning (Renkl, 1997).

In summary, computer-supported script components can be designed to facilitate specific process dimensions of argumentative knowledge construction. Script components that "micromanage" discourse on an epistemic dimension may cause learners to focus on solving the task at hand without elaborating the learning material. In order to foster the elaboration of the learning material and individual knowledge acquisition, script components may need to target not only the epistemic activities, but also focus on social modes of co-construction in argumentative discourse (see Herrenkohl \& Guerra, 1998; Palincsar \& Herrenkohl, 1999). Conversely, script components that are aimed at formal aspects of argument construction without additionally fostering epistemic activities or social modes of co-construction may not be able to help learners achieve better results than without support from a script. Content-independent argumentative script components may aid elaboration, but hold the danger that learners may not be able to select the appropriate concepts that are supposed to be elaborated. The social script component of this study, in contrast, managed to not only facilitate transactive discourse, but also supported the epistemic activities of learners. This indicates that transactivity can be essential to argumentative knowledge con- 
struction and can be facilitated beyond the levels that collaborative learners would spontaneously achieve (Teasley, 1997).

\section{FUTURE RESEARCH}

CSCL environments offer a suitable context for scripting the interaction of learners. Clearly, there is further need to examine beneficial interactions of script components for CSCL, for example, investigating epistemic script components which do not micromanage interaction of learners in combination with social and argumentative script components (see Ertl, Kopp, \& Mandl, this volume). Individual cognitive processes and their relationship to various process dimensions and outcomes of argumentative knowledge construction may explain to a greater extent how learners benefit from argumentative knowledge construction scenarios. Text-based CSCL may provide a unique opportunity for investigating the cognitive processes of learners. While engaging in written communication, learners may simultaneously provide information about their cognitive activities through think-aloudtechniques. We also need to better understand how scripts interact with learners' prior knowledge and skills, which may be represented as internal scripts in contrast to external, computer-supported scripts (Carmien, Kollar, G. Fischer, \& F. Fischer, this volume). Therefore, an important question for future research of CSCL environments is how scripts can be designed not to substitute, but to facilitate discourse and cognitive activities related to individual acquisition of knowledge. In these terms, we need to further investigate the interaction of different script components that may be adapted to the already existing internal scripts. Design environments need to be developed in order to improve the impact of computer-supported script research in practice at schools and universities. These environments should facilitate the adaptive combination of script components with different representations that can be used relatively independent of the computer support available in classrooms.

\section{ACKNOWLEDGEMENTS}

The studies have been funded by the Deutsche Forschungsgemeinschaft (DFG) and the Kaleidoscope Network of Excellence within a European research team entitled "Computer-Supported Scripting of Interaction in Collaborative Learning Environments". 


\section{REFERENCES}

Andriessen, J. E. B., Baker, M., \& Suthers, D. (Eds.). (2003). Arguing to learn. Confronting cognitions in computer-supported collaborative learning environments. Dordrecht: Kluwer.

Baker, M. (2003). Computer-mediated argumentative interactions for the co-elaboration of scientific notions. In J. Andriessen, M. Baker, \& D. Suthers (Eds.), Arguing to learn: confronting cognitions in computer-supported collaborative learning environments (Vol. 1, pp. 1-25). Dordrecht: Kluwer.

Baker, M., \& Lund, K. (1997). Promoting reflective interactions in a CSCL environment. Journal of Computer Assisted Learning, 13, 175-193.

Brown, A. L., \& Palincsar, A. S. (1989). Guided, cooperative learning and individual knowledge construction. In L. B. Resnick (Ed.), Knowing, learning, and instruction. Essays in the honour of Robert Glaser (pp. 393-451). Hillsdale, NJ: Lawrence Erlbaum Associates.

Chi, M. T. H., Bassok, M., Lewis, M. W., Reimann, P., \& Glaser, R. (1989). Self-explanations: How students study and use examples in learning to solve problems. Cognitive Science, 13, 145-181.

Cohen, E. G. (1994). Restructuring the classroom: Conditions for productive small groups. Review of Educational Research, 64, 1-35.

Dillenbourg, P. (2002). Over-scripting CSCL: The risks of blending collaborative learning with instructional design. In P. A. Kirschner (Ed.), Three worlds of CSCL: Can we support CSCL? (pp. 61-91). Heerlen: Open Universiteit Nederland.

Dufresne, R. J., Gerace, W. J., Thibodeau Hardiman, P., \& Mestre, J. P. (1992). Constraining novices to perform expertlike problem analyses: Effects on schema acquisition. The Journal of the Learning Sciences, 2(3), 307-331.

Fischer, F., Bruhn, J., Gräsel, C., \& Mandl, H. (2002). Fostering collaborative knowledge construction with visualization tools. Learning and Instruction, 12, 213-232.

Herrenkohl, L. R., \& Guerra, M. R. (1998). Participant structures, scientific discourse, and student engagement in fourth grade. Cognition and Instruction, 16, 433-475.

Jeong, H., \& Chi, M. T. H. (1999). Constructing shared knowledge during collaboration and learning. Paper presented at the AERA Annual Meeting, Montreal, Canada.

King, A. (1999). Discourse patterns for mediating peer learning. In A. M. O’Donnell \& A. King (Eds.), Cognitive perspectives on peer learning (pp. 87-115). Mahwah, NJ: Lawrence Erlbaum Associates

Kollar, I., Fischer, F., \& Slotta, J. D. (2005). Internal and external collaboration scripts in web-based science learning at schools. In T. Koschman, D. Suthers, \& T.W. Chan (Eds.), Computer Supported Collaborative Learning 2005: The Next 10 Years! (pp. 331-340). Mahwah, NJ: Lawrence Erlbaum Associates.

Kuhn, D., Shaw, V., \& Felton, M. (1997). Effects of dyadic interaction on argumentative reasoning. Cognition and Instruction, 15(3), 287-315.

Larson, C. O., Dansereau, D. F., O’Donnell, A. M., Hytecker, V. I., Lambiotte, J. G., \& Rocklin, T. R. (1985). Effects of metacognitive and elaborative activity on cooperative learning and transfer. Contemporary Educational Psychology, 10, 342-348.

Leitão, S. (2000). The potential of argument in knowledge building. Human Development, 43, 332-360.

Mäkitalo, K., Weinberger, A., Häkkinen, P., Järvelä, S., \& Fischer, F. (2005). Epistemic cooperation scripts in online learning environments: Fostering learning by reducing uncertainty in discourse? Computers in Human Behavior, 21(4), 603-622.

Mandl, H., Gruber, H., \& Renkl, A. (1996). Communities of practice toward expertise: Social foundation of university instruction. In P. B. Baltes \& U. Staudinger (Eds.), Interactive 
minds. Life-span perspectives on the social foundation of cognition (pp. 394-411). Cambridge, MA: Cambridge University Press.

Marttunen, M., \& Laurinen, L. (2001). Learning of argumentation skills in networked and face-to-face environments. Instructional Science, 29, 127-153.

Means, M. L., \& Voss, J. F. (1996). Who reasons well? Two studies of informal reasoning among children of different grade, ability and knowledge levels. Cognition and Instruction, 14, 139-178.

O'Donnell, A. N., \& Dansereau, D. F. (1992). Scripted cooperation in student dyads: A method for analyzing and enhancing academic learning and performance. In R. HertzLazarowitz \& N. Miller (Eds.), Interactions in cooperative groups. The theoretical anatomy of group learning (pp. 120-141). Cambridge, MA: Cambridge University Press.

Palincsar, A. S., \& Herrenkohl, L. R. (1999). Designing collaborative contexts: Lessons from three research programs. In A. M. O'Donnell \& A. King (Eds.), Cognitive perspectives on peer learning (pp. 151-177). Mahwah, NJ: Lawrence Erlbaum Associates.

Pea, R. D. (1994). Seeing what we build together: Distributed multimedia learning environments for transformative communications. Special Issue: Computer support for collaborative learning. Journal of the Learning Sciences, 3(3), 285-299.

Reiser, B. J. (2002). Why scaffolding should sometimes make tasks more difficult for learners. In G. Stahl (Ed.), Proceedings of the Computer Support for Collaborative Learning: Foundations for a CSCL Community - CSCL 2002 (pp. 255-264). Boulder, CO: Lawrence Erlbaum Associates.

Renkl, A. (1997). Lernen durch Lehren - Zentrale Wirkmechanismen beim kooperativen Lernen [Learning through teaching - central mechanisms in cooperative learning]. Wiesbaden: Deutscher Universitäts-Verlag.

Scardamalia, M., \& Bereiter, C. (1996). Computer support for knowledge-building communities. In T. Koschmann (Ed.), CSCL: Theory and practice of an emerging paradigm (pp. 249-268). Mahwah, NJ: Lawrence Erlbaum Associates.

Teasley, S. (1997). Talking about reasoning: How important is the peer in peer collaboration? In L. B. Resnick, R. Säljö, C. Pontecorvo, \& B. Burge (Eds.), Discourse, tools and reasoning: Essays on situated cognition (pp. 361-384). Berlin: Springer.

Toulmin, S. (1958). The uses of argument. Cambridge, MA: Cambridge University Press.

Voss, J. F., \& van Dyke, J. A. (2001). Argumentation in psychology: Background comments. Discourse Processes, 32(2\&3), 89-111.

Weinberger, A. (2003). Scripts for computer-supported collaborative learning. Effects of social and epistemic collaboration scripts on collaborative knowledge construction. Doctoral thesis. Ludwig-Maximilian University, Munich. Available at: http://edoc.ub.unimuenchen.de/archive/00001120/01/Weinberger_Armin.pdf.

Weinberger, A., Ertl, B., Fischer, F., \& Mandl, H. (2005). Epistemic and social scripts in computer-supported collaborative learning. Instructional Science, 33(1), 1-30.

Weinberger, A., \& Fischer, F. (2006). A framework to analyze argumentative knowledge construction in computer-supported collaborative learning. Computers \& Education, 46, 71-95.

Weinberger, A., Reiserer, M., Ertl, B., Fischer, F., \& Mandl, H. (2005). Facilitating collaborative knowledge construction in computer-mediated learning with cooperation scripts. In R. Bromme, F. Hesse, \& H. Spada (Eds.), Barriers and biases in computer-mediated knowledge communication - and how they may be overcome (pp. 15-37). Boston: Kluwer.

Weinberger, A., Stegmann, K., \& Fischer, F. (2005). Computer-supported collaborative learning in higher education: Scripts for argumentative knowledge construction in distributed groups. In T. Koschmann, D. Suthers, \& T. W. Chan (Eds.), Computer Supported 
Collaborative Learning 2005: The Next 10 Years! (pp. 717-726). Mahwah, NJ: Lawrence Erlbaum Associates.

Weiner, B. (1985). An attributional theory of achievement motivation and emotion. Psychological Review, 92, 548-573. 